\title{
The Role of Program Consistency in a Summer Therapeutic Camp for Students with Autism Spectrum Disorder
}

\author{
Colleen Quinn ${ }^{1}$, Ashley Nowosielski ${ }^{1}$, Tom Kitchen ${ }^{1} \&$ Phillip J. Belfiore ${ }^{1}$ \\ ${ }^{1}$ Department of Special Education, Mercyhurst University, Erie, Pennsylvania, USA \\ Correspondence: Phillip J. Belfiore, Department of Special Education, Mercyhurst University, 501 East $38^{\text {th }}$ \\ Street, Erie, Pennsylvania, 16546, USA. Tel: 1-814-824-2267. E-mail: pbelfiore@mercyhurst.edu
}

Received: June 18, 2014

doi:10.5539/jel.v3n3p95

\author{
Accepted: July 8, $2014 \quad$ Online Published: August 14, 2014 \\ URL: http://dx.doi.org/10.5539/jel.v3n3p95
}

\begin{abstract}
Although evidenced-based practices, delivered with procedural integrity are increasingly common in the field of autism, generalizing those practices to less traditional settings is not. The present study, conducted at a summer therapeutic camp used a single subject multiple baseline across participants research design to evaluate the effects of contingent reinforcement utilizing both a variable-interval (VI) 5-minute variable-interval Differential Reinforcement of Other behaviors (VDRO) schedule of reinforcement and a VI 5-minute momentary DRO (MDRO) schedule of reinforcement, combined with token delivery and response cost procedure on increasing compliance and decreasing disruptive behaviors for three, 8-year old males with developmental disabilities. Results are discussed in light of the positive role summer therapeutic camps may play for students with autism spectrum disorder (ASD), and the critical role teachers and staff play in precisely delivering evidenced-based practices, especially in more non-traditional, community-centered educational settings.
\end{abstract}

Keywords: autism, single subject research, summer therapeutic camp, compliance, differential reinforcement

\section{Introduction}

\subsection{Introduction of the Problem}

Increased awareness of individuals diagnosed with Autism Spectrum Disorder has been accompanied by a corresponding growth in the number of professionals packaging and marketing interventions. Researchers (e.g., Belfiore, Fritts, \& Herman, 2008; Kitchen, Belfiore, \& Kitchen, 2010; Van Buskirk \& Simpson, 2013) suggest the scientific community's lack of a single, definitive causal theory for Autism Spectrum Disorder (ASD) may be a contributing factor to this plethora of intervention types and variations. In addition, this variability in treatment approaches may also be attributed to other factors, including philosophical/theoretical differences amongst professionals in the fields of education, psychology, psychiatry, and medicine (Kitchen et al., 2010; Scheuermann, Webber, Boutot, \& Goodwin, 2003; Simpson, 2005). Regardless of theoretical causation or professional preference, more critical questions to be answered surrounding the variation in, and/or multiplicity of interventions for students with ASD are: (a) is there evidence of effectiveness? (b) is there fidelity of implementation? and (c) has the evidence of effectiveness and fidelity of implementation been generalized to more unique environments outside the typical classroom?

\subsection{Importance of the Problem and Relevant Scholarship}

Evidence-based instructional practices may be defined as the integration of research-validated instructional strategies having an established history of yielding positive results, with practical educational expertise (Odom, Brantlinger, Gersten, Horner, Thompson, \& Harris, 2005; Schlosser, 2009; Schlosser \& Raghavedra, 2004). For example, Odom et al. (2003), in a review of instructional interventions with young children with ASD, identify both direct instruction and differential reinforcement as having established a record of effectiveness, validated by a sound empirical research base. Additionally, discrete trial instruction (DTI) (Belfiore et al., 2008; Leblanc, Ricciardi, \& Luiselli, 2005; Ryan, Hughes, Katsiyannis, McDaniel, \& Sprinkle, 2011; Simpson, 2005) and applied behavior analysis (Simpson, 2005; Zane, Davis, \& Rosswurm, 2008) have established a similar record of effectiveness with ASD, as well as a sound research base.

While the field of special education recognizes the need for implementing evidence-based instructional practices, researchers warn that these practices are at times being implemented inconsistently in educational settings 
(Belfiore, et al., 2008; Detrich, 1999; Odom et al., 2005; Shriver, 2007), thus compromising the probability of intervention success. Without consistent implementation of precise practices (i.e., procedural fidelity) student learning may suffer. Procedural fidelity, or procedural integrity, has been described as the degree to which an intervention (i.e., independent variable) is implemented as intended (Peterson, Horner, \& Wonderlich, 1982). In other words, procedural fidelity may be determined by how closely an interventions' implementation matches its' written description. Whereas, earlier reviews of empirical studies showed that only $15.8 \%$ (Gresham, Gansle, \& Noell, 1993a), 14.9\% (Gresham, Gansle, Noell, Cohen, \& Rosenblum, 1993b) and 18\% (Wheeler, Baggett, Fox, \& Blevins, 2006) of studies defined, analyzed, and reported treatment fidelity data; a more recent review and analysis (Barnett et al., 2013) showed increased emphasis on treatment fidelity, reporting that $70 \%$ of their pool of 266 school-based research articles published between 2005-2012 included fidelity of intervention data.

Although evidenced-based practices with students with ASD have been routinely documented (question a. above) and procedural fidelity data has been increasingly reported on those practices (question b. above), few studies address the generalization of those practices in unstructured, non-education setting such as neighborhood or local community locations (question c. above). For example, in an analysis of participant and setting characteristics in autism intervention research from 1995 through 2009, Crosland, Clarke, and Dunlap (2013) identify only six $(2.0 \%)$ intervention studies $(\mathrm{n}=273)$ citing community (e.g., parks, stores, recreation facilities, restaurants) as the primary intervention environment. The other $98 \%$ of reported setting included general education, special education, home, clinic, and short-term residential facilities (Crosland et al., 2013). Other traditional, structured educational settings reported in the special education literature include such locations as a day treatment centers (Tarbox, Ghezzi, \& Wilson, G., 2006), state-approved private education facilities (Belfiore et al., 2008), private schools (Leblanc et al., 2005), public school-resource rooms (Knight, Spooner, Browder, Smith, \& Wood, 2013), and special education classrooms (Reynhout \& Carter, 2007). Crosland et al. (2013) suggest that the limited use of community setting may be the result of procedural and methodological issues, resulting in difficulties in conducting interventions in those less than traditional settings. If interventions for students with ASD are to be deemed effective, those results must be documented in other locations where students spend time, including community settings.

Without the documentation of precisely defined-consistently implemented evidenced-based practices occurring across multiple locations (e.g., school and community locations), there exists a gap between what is described in the ASD literature and what goes on in the real world of students with ASD. Several studies suggest summer treatment camps delivering innovative strategies have been underutilized and understudied, but hold much promise in both the acquisition of new skills and the maintenance of existing skills for students with ASD (e.g., Liu \& Meaney, 2011; Walker, Barry, \& Bader, 2010). Whereas the unstructured nature of summer may be overwhelming for children with ASD and their parents (Brookman et al., 2003), Walker et al. (2010) suggest summer treatment camps provide much needed structure to the summer months for students with ASD, as well as a respite for their parents and caregivers. Additionally, participation in summer treatment or recreation camps for students with ASD may result in improvement in social, communication, and motor skill development (Liu \& Meaney, 2011), as well as increased inclusive opportunities (Brookman et al., 2003). A small number of recent studies found in the peer-reviewed literature do address opportunities summer treatment camps hold for students with ASD. Those studies (a) highlight overall program goals and design (Lui \& Meaney, 2011), (b) describes summer camp operations (Brookman et al., 2003), and (c) report parent and staff perceptions of the role summer camps play in building social skills for children with ASD (Lopata, Thomeer, Volker, \& Nida, 2006; Walker et al., 2010). Unfortunately, no specific study empirically evaluated evidenced-based practices, and the fidelity of those practices in a summer camp setting.

\subsection{Purpose of Research}

A lack of procedural fidelity and setting generalization of evidence-based practices results in a disconnection between research-validated practices and the "real-world" implementation of those practices. This is especially the case when the strategies themselves appear simple at first glance, but actually involve complex relationships between multiple contingencies or schedules of reinforcement that are implemented simultaneously. The purpose of this study was to examine the effects of a reinforcement contingency incorporating two simultaneous VI 5-minute DRO schedules combined with token reinforcement and response-cost on the compliance to directives and frequency of disruptive behaviors of three male students in a summer therapeutic camp for children with ASD. 


\section{Method}

\subsection{Participants and Setting}

Three male students with a diagnosis of Autism Spectrum Disorder (ASD) attending a Summer Therapeutic Activity Program (STAP) participated in the current study. All three students were chosen for the study based on (a) behavioral data recorded during pre-baseline conditions, and (b) discussions with the students' individual Behavior Specialist Consultants. All three participants demonstrated similar levels of noncompliance and disruptive behaviors as well as good general verbal and social skills. The participants were all male due to the fact that the possible participant pool consisted of an all-male population.

Chris, 8 years old, was diagnosed with Asperger's Disorder at the time the study was conducted. He was chosen to be part of the study based on Behavior Specialist Consultant's recommendations, and his display of disruptive behavior upon entering the STAP. David, 8 years old, was diagnosed with Attention Deficit Hyperactivity Disorder (ADHD) and Pervasive Developmental Disorder (PDD) at the time the study was conducted. He was chosen to be part of the study based on Behavior Specialist Consultant's recommendations, and his display of target tantrum and aggressive behavior upon entering the STAP. Joe was diagnosed with R/O Autistic Disorder and ADHD and was also 8 years old at the time the study was conducted. He was chosen to be part of the study based on Behavior Specialist Consultant's recommendations and his display of noncompliant behavior. Chris primarily engaged in tantrum behaviors including screaming, yelling, and/or crying. David primarily displayed aggression (hitting, pushing, throwing objects at others), noncompliance (refusal to complete to complete tasks for extended periods of time), and disruptive behaviors (interrupting peer activities, talking out). Joe primarily engaged in disruptive behavior (interrupting peer activities, talking out, floor dropping), aggression (hitting, throwing objects, kicking, scratching others), tantrum, and noncompliance (refusal to complete tasks for extended periods of time).

The STAP consisted of a total of 54 children, with disabilities including Autism, ADHD, PDD, and Disruptive Disorder, ranging in age from 5-16 years of age. The STAP ran for a total of 8 weeks. The STAP setting included a total of five rooms, as well as outdoor playgrounds, and swimming pool. Chris, David, and Joe were in the same room. Their room contained 6 total children and 3 full time summer staff. There were a number of interns and Behavior Specialist Consultants that assisted the full time summer staff when necessary. The first and second authors were members of the STAP staff. The three participants spent the camp days together for the entirety of the STAP. The STAP consisted of activities that focused on improving social skills, both individually and in small group settings. Typical daily activities included social skills trainings, facilitated small group play activities, structured outdoor play activities, and weekly field trips, including swimming lessons.

\subsection{Dependent Measures, Data Collection, and Materials}

Data were collected using a computer-generated printable data sheet throughout the duration of each session. There was a total of 20 sessions, each lasting 90-minutes, and taking place between 12:30 p.m. and 2:00 p.m. The 90-minute session time frame allowed the teacher to incorporate the directives into the natural context of a STAP day. The primary dependent measure was percentage compliance to adult-initiated, group or individual directives within 5-seconds of the directive. Examples of group directives included "Line up," "Go to your seats," "Clean up," while examples of individual directives include "Put your lunchbox away," "Pick up your papers," "Throw away your garbage." Compliance data were recorded by taking the number of adult-initiated, group or individual directives complied with, divided by the total number of directives presented during each 90-minute session. Average frequency of directives delivered per baseline session was 19.5 (range 4-30), while the average frequency of directives delivered per intervention session was 19.0 (range 4-30).

The secondary dependent measure, frequency of disruptive behavior, was defined as vocalizations above conversational level (yelling, screaming), whining, crying, floor-dropping lasting a minimum of 5 seconds, hitting, kicking, slapping, spitting, pinching, scratching, and/or any inappropriate physical contact. Disruptive behavior was recorded by counting the total frequency of occurrence during each 90-minute session.

Materials used during this study included printable money identified as "camp cash" for all camp attendants, plastic bags for each camper that served as "banks" to hold their earned "camp cash", and tangible reinforcers such as items as edibles, small toys, school supplies, and books. During the intervention phase, staff (first and second author) used a portable $\mathrm{CD}$ player and a manufactured $\mathrm{CD}$ that denoted the variable interval times with an audible tone. 


\subsection{Single Subject Experimental Design}

The study incorporated a multiple baseline across students' design in which staff compared the baseline condition to intervention condition. Intervention was introduced sequentially across the three students once the data from the previous student demonstrated a stable baseline. The sequential introduction of intervention when using a multiple baseline design established control within and across data series for each participant. More specifically, a multiple baseline design establishes experimental control by noting (a) the change in the dependent measure as each participant moves from baseline phase to intervention phase and (b) the change in the dependent measure for each participant once the intervention phase is introduced, while behavior remains unchanged for other participants continuing under the baseline phase (Barlow, Nock, \& Hersen, 2009).

\subsection{Procedures}

Introduced at the onset of the summer camp, and remaining in effect throughout all phases of this study was a camp-wide token reinforcement and response-cost system (See Table 1 for written instructions provided to all STAP staff at the beginning of the summer camp). All STAP staff (including the first and second authors) participated in a camp-wide, week long training the week before camp began. The week was broken into a series of trainings modules, with one day devoted to token reinforcement systems and response cost procedures, which included a presentation and hand-outs (See Table 1).

As written, the STAP token system delivered tokens (i.e., camp cash) for the students displaying appropriate behaviors (e.g., attending skills, participation, playing appropriately, helping peers), but not problem behavior (e.g., tantrums, aggression, elopement, noncompliance). In more precise terms, the token system was a loosely structured procedure based upon a Differential Reinforcement of Other Behavior (DRO) reinforcement schedule (Reynolds, 1961), in which reinforcement is provided following some unit of time in which a specified behavior does not occur. In this case, "problem" behaviors (above) were identified that would prevent program participants from accessing tokens. Unfortunately, as noted anecdotally by the first and second author, the token delivery and exchange procedures were differentially implemented across classrooms, dependent on (a) classroom age group, (b) individual target behaviors, (c) camp activities, (d) time of day, and (e) staff preferences.

The camp store was an integral part of the study's setting. The camp store was a room within the building that was filled with items serving as potential reinforcers where participants went once a day to exchange any earned tokens. The camp store included eight tables covered with tangibles such as food, toys, books, and vouchers for spending time with specific STAP staff. Parents of all the STAP participants were asked to provide a list of their child's preferred reinforcers at the onset of the STAP. A head table served as the token exchange area where one of the authors would help students exchange tokens for chosen reinforcers. At the end of each day (2:30 p.m.), students were taken to the camp store to exchange their earned tokens for tangible items and/or activities. Students also had the option to save their earned tokens for larger items. Delayed items included time with specific STAP staff, individualized choice activities (i.e., going on a walk), or time with the therapy dog that made weekly visits to the STAP.

In addition to the STAP token system, a camp-wide response-cost system was also in place. Response-cost consisted of procedures where students lost all camp tokens earned if noncompliance to adult directives and/or disruptive behavior were observed at any time throughout the day. Once tokens were removed, the eligibility to begin to earn tokens again required that students wait 5 minutes from the time the tokens were removed, without displaying noncompliant and disruptive behaviors.

Table 1. STAP guideline for program-wide token reinforcement and response-cost procedures

Camp Cash is a form of a token economy that we will be using as a reinforcement strategy for the campers. This token economy will provide the campers' opportunities to earn reinforcement contingent on displaying appropriate and desired behaviors as well as not displaying inappropriate target problem behaviors.

Token Economy: A system where participants earn generalized conditioned reinforcers (i.e., tokens, chips, points, etc.) as an immediate consequence for specific behaviors. Participants can accumulate tokens and exchange them for items and activities from an array of backup reinforcers.

How do we implement the Camp Cash system?

This form of a token economy is a reinforcement system that is geared at increasing the probability of 
target replacement behaviors. Camp staff will provide reinforcement for those behaviors you want to see more of (appropriate/acquisition behaviors) and will not provide reinforcement for those behaviors intended for reduction (inappropriate/problem behaviors).

Camp staff will follow the protocol below when using the Camp Cash token economy:

1. Each camper will have a "bank" to keep their cash in (Ziploc bags with the camper's name on it.)

2. Issue camp cash contingent upon acquisition behaviors such as:

a. Perspective Taking

b. Emotional Reciprocity (Empathy)

c. Coping Skills

d. Joint Attention

e. Conversation Skills (Initiating and Responding)

f. Appropriate Play (Pretend play, Sharing, and Turn Taking)

3. DO NOT issue camp cash when observing target problems behaviors such as:
a. Tantrum
b. Aggression
c. Self-Injurious Behavior
d. Noncompliance
e. Elopement
f. Property Destruction

4. At the end of each day, each group will have an opportunity to go to the Camp Store to cash in. During this time, campers can choose to exchange their earned camp cash to purchase prizes or they can choose to save their camp cash for a bigger prize. They may also use some of their camp cash to buy camp store items and keep any remainder for the following day(s).

What do we do if a camper engages in problem behaviors?

After the FIRST week, staff will implement a Response Cost procedure.

How do we implement a Response Cost procedure?

1. Without saying anything to the camper, take all of their camp cash from their "bank," including camp cash that may have been saved from previous days. This may seem like a harsh consequence, but we want the response cost that is meaningful and effective. Be prepared for an escalation of problem behavior once you take the camp cash away.

2. Try not to talk to the camper too much while implementing the response cost procedure. If they display any problem behaviors, simply direct them to a "cool down" area where they can calm down.

3. Once the camper is calm, you may then review with them the reason(s) why they lost their camp cash.

4. The camper is NOT eligible to earn camp cash until 5 minutes has passed after the occurrence of problem behavior has ended. After 5 minutes passes and the camper has displayed no problem behavior(s), they are eligible to earn camp cash again and you can implement the token economy procedures.

5. DO NOT talk to campers about the problem behavior/incident before or during the incident. By removing the camp cash, you are delivering the only needed consequence for the behavior. Talking to/ engaging them while they are in the midst of problem behavior will only reinforce inappropriate behavior that we want to reduce.

6. TRY NOT to give warnings about taking camp cash away, just take it! These campers are smart and the response cost procedures will quickly teach them what happens if they engage in problem behavior if it is implemented correctly.

Description: These procedures were in place prior to, and throughout all phases of the study. 


\subsubsection{Baseline}

Overall, the baseline condition represented the typical STAP classroom as described above. More specifically, the target classroom inconsistently used the token delivery and response cost procedures, not following written STAP guidelines. For example, it was observed during baseline that multiple STAP staff delivered tokens regardless of defined appropriate or problem behavior described in the written STAP guidelines (see Table 1). Students earned varying amounts of tokens depending on idiosyncratic staff delivery of reinforcement, resulting in subjective and inconsistent levels of reinforcement. For example, during the baseline condition, participants displaying compliance to directives and low levels of disruptive behavior often received less reinforcement than those with higher rates of disruptive behavior, and little compliance to directives. Anecdotal observations during baseline showed reinforcement delivery varied, depending on the daily timing of activities (e.g., reinforcement was dense at the beginning of each day and thinned out as the day progressed), and the activity structure level (e.g., unstructured activities resulted in less reinforcement than group or more structured activities), regardless of compliant or disruptive behaviors occurring. Additionally during baseline, response-cost procedures were observed to be inconsistently implemented, depending on which STAP staff observed target behaviors. Across session inconsistencies included (a) when response-cost was implemented, (b) how many tokens were removed, and (c) how long participants had to wait to begin earning tokens again.

\subsubsection{Intervention}

Whereas in the baseline phase, when numerous STAP staff were involved, during the intervention phase specifically identified STAP staff (the first and second authors) were selected in an attempt to deliver a more consistent intervention. Additionally to establish a more consistent token delivery system, a VI5 minute schedule was applied to the existing STAP token economy. The schedule audio prompts were delivered in the form of a cuing CD. Tokens were delivered according to two separate yet simultaneous VI 5-minute DRO-based schedules (interval range 3-7 minutes). The first schedule was most representative of a variable DRO (VDRO) schedule (Patterson, Jones, Whittier, \& Wright, 1965; Topping \& Crowe, 1974), in which reinforcement is delivered contingent upon the absence of any specific noncompliant behaviors throughout the entire interval. The second simultaneous schedule was most consistent with a momentary DRO (MDRO) schedule (Barton, Brulle, \& Repp, 1986), in which reinforcement is delivered if none of the specified disruptive behaviors were occurring at the exact time that the interval ended. Tokens were then accumulated and "cashed in" as described at the end of this paragraph. Students lost all camp tokens earned if noncompliance to adult directives and/or disruptive behavior were observed at any time throughout the session. Once tokens were removed, students had to wait 5 minutes, without displaying noncompliant and disruptive behaviors, before the token system was re-instated. Each session during the intervention phase began with the staff-delivered verbal prompt "Now is a good time to earn camp cash by following the rules," Unlike the baseline condition where multiple staff delivered and removed tokens, during the intervention phase of this study, specific STAP staff (the first and second authors) delivered and removed tokens. Similar to baseline, at the end of each session, each participant was able to exchange their earned tokens for reinforcers at the camp store.

The intervention phase was introduced to Chris once stability was achieved during the baseline condition. David and Joe remained in the baseline phase until Chris showed change in level of responding during the intervention phase. Intervention was then introduced subsequently to David and Joe once stability was achieved during their baseline conditions and the previous participant showed change in levels of responding within their current intervention phase. In general, the intervention phase provided a procedurally sound, consistently implemented token delivery, token exchange, and response cost procedures. Follow-up occurred 1 week after the intervention phase ended. The single session included all components used during the intervention phase.

\subsection{Inter-Observer Agreement, Procedural Fidelity, Social Validity}

The primary dependent variable under examination was compliance to directives and the secondary dependent variable was disruptive behavior. Inter-observer agreement (IOA) was conducted during $25 \%$ of all sessions, equally across each student, with the IOA average of $96 \%$ (range $88-100 \%$ ) for the percentage compliance, and IOA of $100 \%$ for frequency of disruptive behavior. IOA was conducted during $19 \%$ of all baseline sessions, and $31 \%$ of all intervention sessions. IOA was calculated by dividing the smaller number by the larger number and multiplying the result by $100 \%$ (Barlow et al., 2009).

Procedural fidelity data were collected during $25 \%$ of the all intervention sessions. The steps listed for procedural integrity included, (a) provides verbal prompt at the onset of the session "Now is a good time to earn camp cash by following the rules," (b) begins internal audio-cuing CD, (c) delivers token (i.e., camp cash) if participant is not engaging in disruptive behavior when cue sounds, (d) implements response cost, removing all 
earned tokens if participant engages in disruptive behavior at any time during the session, (e) takes participants to the camp store to cash in earned tokens for reinforcer. All intervention steps were followed accurately at $100 \%$ during each session in which procedural integrity was recorded.

A social validity survey was given to each participant at the end of the summer program (See Table 2). All three participants answered "yes" to each of the five items on the social validity survey.

Table 2. Participant social validity survey

\begin{tabular}{ll}
\hline Participant & \\
\hline 1. Getting camp cash made it easier for me to follow the rules. & YES/NO \\
2. I liked getting more camp cash. & YES/NO \\
3. I feel like having more camp cash made me happier. & YES/NO \\
4. Losing my camp cash made me wish I would have followed the rules. & YES/NO \\
5. I liked being able to earn more camp cash than other campers in my classroom. & YES/NO \\
\hline
\end{tabular}

\section{Results}

Figures 1 and 2 show the results of (a) the percentage compliance to staff directives, and (b) the frequency of disruptions, for Chris, David, and Joe. Overall, for the three participants, baseline showed low and variable levels of compliance to directives (Figure 1) and variable levels of disruptions (Figure 2). If STAP programming guidelines were effective, baseline would have shown increases in compliance with decreases in disruptions as the summer camp progressed. For all participants, from baseline to intervention phase, there was an increase in the average percentage compliance to adult directives, and a decrease in the average frequency in disruptive behaviors. David and Joe also maintained those increased levels of compliant behavior, and decreased levels of disruptive behavior during the follow-up session (Chris did not participate in any follow-up data sessions).

Chris's compliance during baseline was variable, with the mean percentage of compliance at $77 \%$, and a range of $61-92 \%$. Following the introduction of intervention, Chris's compliance transitioned upward over the next three sessions, maintaining a high level, with a mean compliance of $86 \%$ and a range of $66-100 \%$. His disruptive behaviors ranged from 0-4 instances during baseline, with an average of 1.2 incidents per session. Following the implementation intervention, his behaviors had an initial increase during the first session, but then dropped to zero and remained there over the next 14 sessions. Chris was absent on the final day of camp when follow-up data were collected.

David's compliance throughout baseline averaged $48 \%$ of opportunities with a range of $36-70 \%$ compliance. During the first session in which intervention was introduced, his compliance increased to $100 \%$ and maintained at a high level (an average of $91 \%$ ), with a range from $76-100 \%$. David displayed compliance to $93 \%$ of opportunities during the follow-up session. His disruptive behaviors were highly variable during baseline, ranging from 0-115 incidents per session. During sessions 1, 4, and 9 David had very high levels of disruptive behaviors at 88,18 , and 115 , respectively. During each of these sessions, behaviors occurred on a field trip to the pool. If those three sessions were excluded, David's disruptive behaviors would range between 0-12. Observed disruptive behaviors during intervention ranged from $0-6$ with an average of .88 instances. For David, no disruptive behavior was observed during the follow-up session.

Joe's compliance remained variable throughout baseline, with an average of compliance to $63 \%$ of opportunities per session and ranging from $40-90 \%$. Following the implementation of intervention, his compliance immediately increased to $100 \%$ on the first day of intervention and maintained at a high level throughout the intervention and follow-up phase. His average percentage compliance during intervention sessions was $98.6 \%$, with a range of $93-100 \%$ and his follow-up data was $100 \%$ compliance. Disruptive behaviors during baseline for Joe ranged from 0-8 instances per session, with an average of 2.5 instances. Prior to implementation of the intervention, his behaviors were increasing, and immediately fell to 0 occurrences, where they remained through the entire intervention phase and follow-up.

\section{Discussion}

Detrich (1999) suggested intervention effectiveness is compromised if within session precision and across session consistency are not achieved. To ensure best practices, professionals must affirm a three-part test (a) was 
the intervention effective and social valid (e.g., accountability), (b) was the intervention repeatedly delivered as described (e.g., procedural fidelity), and if those accountable and procedurally consistent interventions have (c) generalizable results in less traditional, community locations meaningful to the life of the student? If educators, clinicians, parents, caregivers, and researchers cannot answer yes to this three-part test, real-world community success for children with ASD may be compromised.

In the present study, (a) yes, evidenced-based practices via applied behavior analysis (DRO, token economy, and response cost) were implemented, effective, and socially validated by the participating students, (b) yes, procedural fidelity data were collected during $25 \%$ of all intervention sessions, and followed accurately $100 \%$ of the time, and (c) yes, the summer therapeutic camp was the primary setting for all phases of the study. More specifically, the results showed that for three students with ASD attending a summer therapeutic camp, implementing an arrangement of DRO contingencies based on a VI5-min audio-cued schedule of corresponding token reinforcement, and response cost procedure was effective in increasing and maintaining compliance to commands while decreasing disruptive behaviors. Baseline data in Figure 1 and 2 showed an average percentage compliance to staff directives at $62 \%$ across all three students (Figure 1), while disruptive behaviors was increasing for Chris and varied greatly for David and Joe (Figure 2). When, during intervention, the same token system and response-cost as described in Table 1 was (a) implemented using two specific DRO contingencies based on a VI 5-minute schedule, (b) monitored by a within session procedural fidelity checklist, and (c) consistently implemented across sessions during the intervention phase, results in compliance increased to an average of $91.8 \%$ across the three students, and disruptions decreased to zero for each of the three students.

The audio-cued, 5-minute VDRO/VMDRO token reinforcement schedule impacted both staff and students. The audio-cue that signaled the VI 5- min interval may have impacted summer staff as a discriminative stimulus, resulting in a more accurate and consistent delivery of reinforcement within and between sessions. The fidelity resulting from the audio-cued, VDRO/MDRO-based token reinforcement schedule may have impacted students by establishing a consistently reinforced learning environment resulting in increased persistence of compliance to staff directives while almost eliminating the occurrence of disruptive behaviors. Anecdotal observations on token delivery during baseline showed reinforcement delivery varying, depending on (a) the daily timing of activities (e.g., reinforcement was dense at the beginning of each day and thinned out as the day progressed), and (b) the activity structure level (e.g., unstructured activities resulted in less reinforcement than group or more structured activities), regardless of compliant or disruptive behaviors occurring.

During intervention, the VI5 min VDRO/MDRO-based token delivery schedule precisely cued staff at 3-min, 5-min, or 7-min, resulting in consistent (ranging from 3 to 7 minutes) within-session token delivery, resulting in approximately 12 tokens per hour. In addition, during intervention, the frequency of disruptive behaviors decreased, resulting in less use of response-cost procedures, allowing for more time to earn tokens. Nevin, Mandell, and Atak (1983), and others (e.g., Mace \& Belfiore, 1990; Nevin, 1992; Parry-Cruwys, Neal, Ahearn, Wheeler, Prechander, Loeb, \& Dube; 2011) suggest that behavior may persist (or resist change) when presented with some disruption or distractor, if that behavior occurs in the presence of a stimulus condition associated with high levels of reinforcement. In the current study, the distractor was staff directives. During baseline, delivered directives resulted in a lower percentage of compliance (i.e., less persistence of compliance to staff directives), whereas during an intervention that produced a consistent level of reinforcement, compliance increased (i.e., more persistence of compliance to staff directives). The distractor was less distracting (i.e., less aversive) under a cued VI5-min VDRO/MDRO-based schedule of reinforcement intervention condition than under a baseline condition where tokens may have been indiscriminately delivered. Additionally, in this study, each intervention session began with the staff-delivered verbal prompt "Now is a good time to earn camp cash by following the rules." This prompt may have served as the stimulus, cueing the student that a more consistent level of reinforcement (VI5-min) is forthcoming, delivered by the first and second authors (who also may have served as a cue for more consistent reinforcement).

Several studies (e.g., Tarbox et al., 2006) suggest that once behavior is occurring at appropriate levels under a specific token reinforcement system, it is useful to thin the reinforcement schedule, to monitor maintenance of behavior change under a less reinforced condition. However, given the basic and applied research in behavioral momentum, thinning schedules of reinforcement in distracting educational environments may be counterproductive (Mace \& Belfiore, 1990; Nevin, 1992).

Several limitations were noted throughout this study. First, the STAP schedule limited the length of this study to eight weeks. Additionally, various activities and field trips interfered with the daily schedule of observations. Second, although the parents of each student provided firsthand input as to the items serving as reinforcers in the 
camp store, a more direct student preference assessment may be more beneficial. Lastly, the intervention included differential reinforcement, a token system, and response cost. Future research may want to isolate each component to allow for a precise explanation for behavior change.

Although anecdotal records presented by both the first and second author showed repeated inconsistencies by summer camp staff of the STAP procedures (Table 1) during baseline, no formal data were collected on procedural integrity during the baseline phase. Future research may want to consider collecting procedural integrity on staff delivery of tokens and response-cost procedures during the baseline condition, especially in such non-traditional setting as summer camp. Although procedural integrity data are not typically collected during baseline sessions (i.e., during the condition when no intervention is in place), integrity data would be warranted when baseline sessions include existing class-wide management procedures. In the case of this study, procedural integrity data collected during baseline sessions (serving as an additional dependent measure) would have allowed a more accurate picture as to the cause of behavior change from baseline to intervention. However, even without such additional baseline data, this study showed that evidenced-based practices can be delivered consistently in a summer therapeutic camp, resulting in a positive effect on the behavior of students with ASD. Finally, the current study illustrates the complexity involved when often-recommended strategies are implemented in the real world. Token systems and differential reinforcement are nothing new in the behavior change literature. The authors contend that further study is needed pertaining to the arrangement of multiple contingencies within multicomponent interventions (e.g., VDRO, MDRO, DR-RCD, token delivery/cash-in, response cost, etc.) guised as seemingly simple interventions consisting of token delivery and provision of back-up reinforcers. Such complexity can create fidelity challenges across several critical components of the contingencies. 

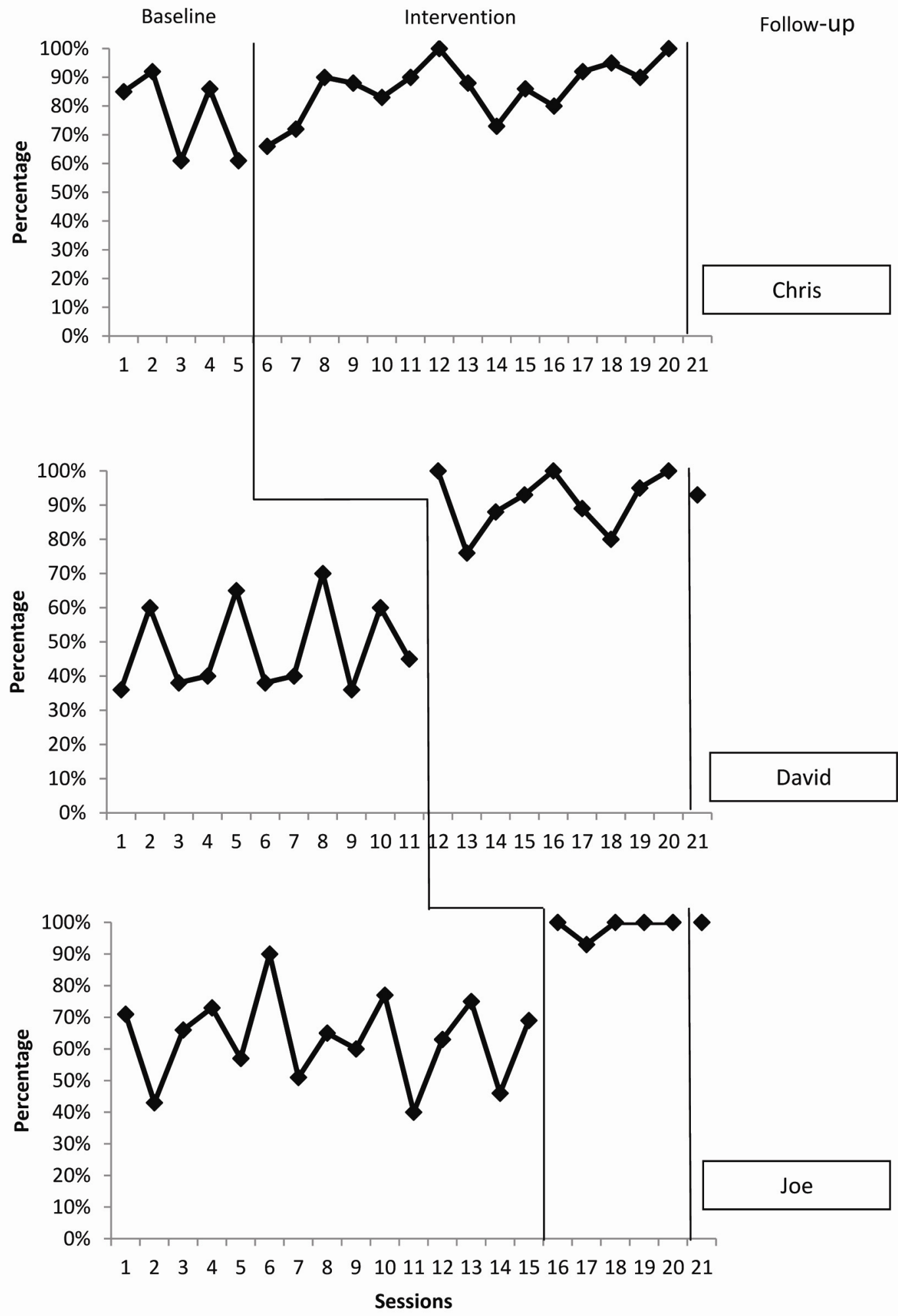

Figure 1. Data show the percentage compliance during 90-min sessions to adult-initiated, group or individual directives for Chris, David, and Joe across baseline, intervention, and follow-up phases 

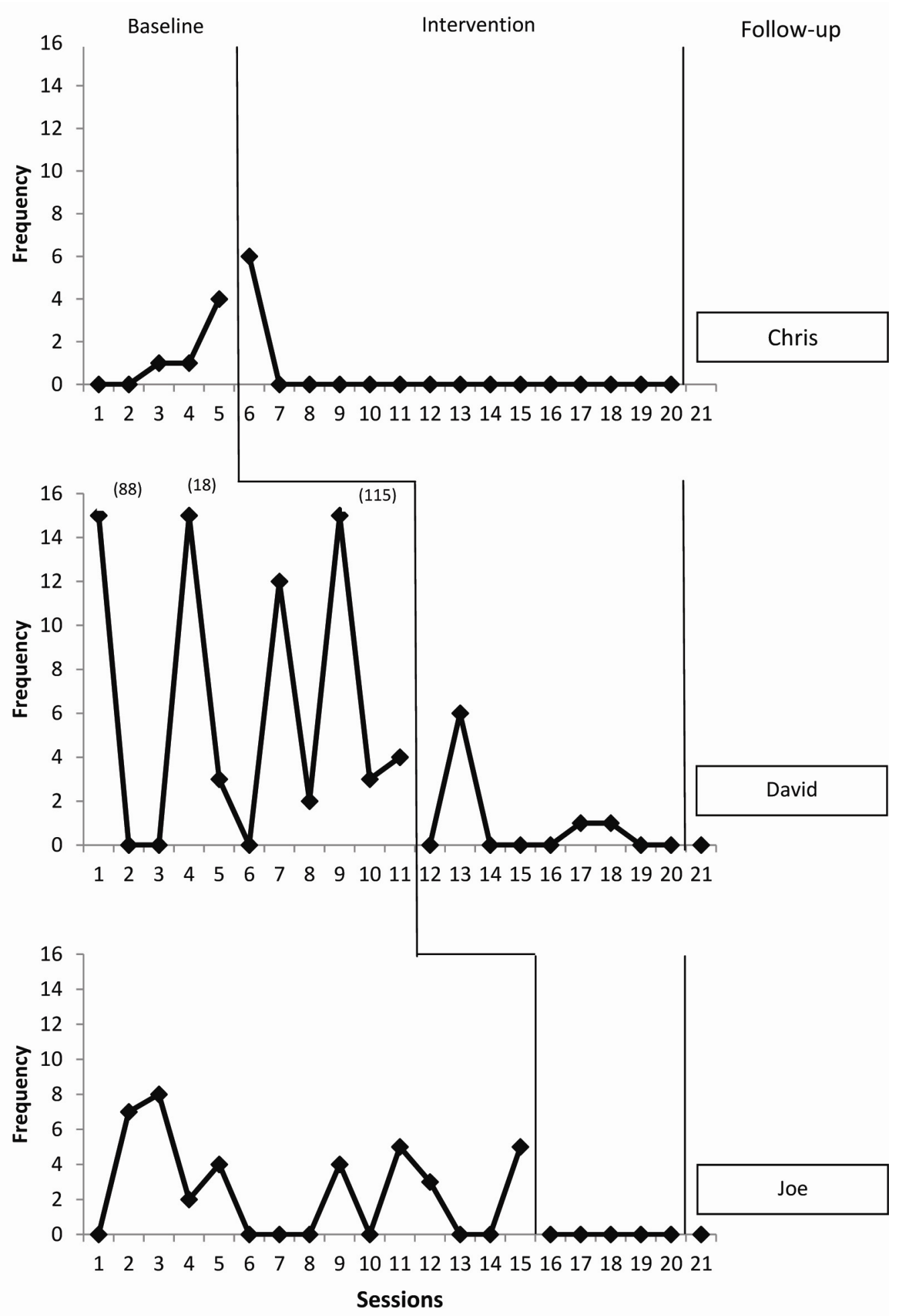

Figure 2. Data show the frequency of disruptive behavior during 90-min session for Chris, David, and Joe across baseline, intervention, and follow-up phases. Note the numbers parentheses for David (sessions 1, 4, 10) represent frequencies beyond the range of $0-16$ 


\section{References}

Barlow, D. H., Kock, M. K., \& Hersen, M. (2009). Single case experimental designs: Strategies for studying behavior change. Boston, MA: Allyn and Bacon.

Barnett, D., Hawkins, R., McCoy, D., Wahl, E., Shier, A., Denune, H., \& Kimener, L. (2013). Methods used to document procedural fidelity in school-based intervention research. Journal of Behavioral Education. http://dx.doi.org/10.1007/s10864-013-9188-y

Barton, L. E., Brulle, A. R., \& Repp, A. C. (1986). Maintenance of therapeutic change by momentary DRO. Journal of Applied Behavior Analysis, 19, 277-282. http://dx.doi.org/10.1901/jaba.1986.19-277

Belfiore, P. J., Fritts, K. M., \& Herman, B. C. (2008). Effects of video self-monitoring on teaching performance: Enhancing staff Discrete Trial Instruction (DTI) in Autistic support classrooms. Focus on Autism and Other Developmental Disabilities, 23, 95-102.

Brookman, L., Boettcher, M., Klein, E., Openden, D., Koegel, R. L., \& Koegel, L. K. (2003). Facilitating social interactions in a community summer camp setting for children with autism. Journal of Positive Behavior Interventions, 5, 249-252. http://dx.doi.org/10.1177/10983007030050040801

Crosland, K. A., Clarke, S., \& Dunlap, G. (2013). A trend analysis of participant and setting characteristics in autism intervention research. Focus on Autism and Other Developmental Disabilities, 28, 159-165. http://dx.doi.org/10.1177/1088357612468029

Detrich, R. (1999). Increasing treatment fidelity by matching interventions to contextual variables within the educational setting. School Psychology Review, 28, 608-620.

Gresham, F. M., Gansle, K. A., \& Noell, G. H. (1993a). Treatment integrity in applied behavior analysis with children. Journal of Applied Behavior Analysis, 26, 257-263. http://dx.doi.org/10.1901/jaba.1993.26-257

Gresham, F. M., Gansle, K. A., Noell, G. H., Cohen, S., \& Rosenblum, S. (1993b). Treatment integrity in school based intervention studies: 1980-1990. School Psychology Review, 22, 254-272.

Kitchen, T., Belfiore, P. J., \& Kitchen H. L. (2010). The necessity of measures of procedural integrity to ensure effective delivery of evidence-based interventions for children with autism spectrum disorders. In M. T. Burton (Ed.), Special Education in the $21^{\text {st }}$ Century (pp. 67-94). Hauppauge, NY: Nova Science Publishers.

Knight, V. F., Spooner, F., Browder, D. M., Smith, B. R., \& Wood, C. L. (2013). Using systematic instruction and graphic organizers to teach science concepts to students with autism spectrum disorders and intellectual disability. Focus on Autism and Other Developmental Disabilities, 28, 115-126. http://dx.doi.org/10.1177/1088357612475301

Leblanc, M. P., Ricciardi, J. N., \& Luiselli, J. K. (2005). Improving discrete trial instruction by paraprofessional staff through an abbreviated performance feedback intervention. Education and Treatment of Children, 28, 76-82.

Lopata, C., Thomeer, M. L. Volker, M. A., \& Nida, R. E. (2006). Effectiveness of a cognitive-behavioral treatment on the social behaviors of children with Asperger disorder. Focus on Autism and Other Developmental Disabilities, 21, 237-244. http://dx.doi.org/10.1177/10883576060210040501

Lui, T., \& Meaney, K. (2011). Developing a recreational summer camp for children with autism spectrum disorder. Palaestra, 25, 27-32.

Mace, F. C., \& Belfiore, P. J. (1990). Behavioral momentum in the treatment of escape-motivated stereotypy. Journal of Applied Behavioral Analysis, 23, 507-514. http://dx.doi.org/10.1901/jaba.1990.23-507

Nevin, J. A. (1992). An integrative model for the study of behavioral momentum. Journal of the Experimental Analysis of Behavior, 57, 301-316. http://dx.doi.org/10.1901/jeab.1992.57-301

Nevin, J. A., Mandell, C., \& Atak, J. (1983). The analysis of behavioral momentum. Journal of the Experimental Analysis of Behavior, 39, 49-59. http://dx.doi.org/10.1901/jeab.1983.39-49

Odom, S. L., Brantlinger, E., Gersten, R., Horner, R. H., Thompson, B., \& Harris, K. R., (2005). Research in special education: Scientific methods and evidence-based practices. Exceptional Children, 71, 137-148. http://dx.doi.org/10.1177/001440290507100201

Parry-Cruwys, D. E., Neal, C. M., Ahearn, W. A., Wheeler, E. E., Prechander, R., Loeb, M. B., \& Dube, W. V. (2011). Resistance to disruption in a classroom setting. Journal of Applied Behavior Analysis, 44, 363-367. http://dx.doi.org/10.1901/jaba.2011.44-363 
Patterson, G. R., Jones, R. Whittier, J., \& Wright, M. A. (1965). A behavior modification technique for the hyperactive child. Behavior Research and Therapy, 2, 217-226. http://dx.doi.org/10.1016/0005-7967(64)90019-1

Peterson, L., Horner, A., \& Wonderlich, S. (1982). The integrity of independent variables in behavior analysis. Journal of Applied Behavior Analysis, 15, 477-492. http://dx.doi.org/10.1901/jaba.1982.15-477

Reynhout, G., \& Carter, M. (2007). Social story efficacy with a child with autism spectrum disorder and moderate intellectual disability. Focus on Autism and Other Developmental Disabilities, 22, 173-182.

Reynolds, G. S. (1961). Behavioral contrast. Journal of the Experimental Analysis of Behavior, 4, 57-71. http://dx.doi.org/10.1901/jeab.1961.4-57

Ryan, J. B., Hughes, E. M., Katsiyannis, A., McDaniel, M., \& Sprinkle, C. (2011). Research-based educational practices for students with autism spectrum disorders. Teaching Exceptional Children, 43, 56-64.

Scheuermann, B., Webber, J., Boutot, E. A., \& Goodwin, M. (2003). Problems with personnel preparation in autism spectrum disorders. Focus on Autism and Other Developmental Disabilities, 18, 197-206. http://dx.doi.org/10.1177/10883576030180030801

Schlosser, R. W. (2009). The role of single-subject experimental designs in evidence-based practice times. National Center for the Dissemination of Disability Research.

Schlosser, R. W., \& Raghavedra, P. (2004). Evidence-based practice in augmentative and alternative communication. Augmentative and Alternative Communication, 20, 1-21. http://dx.doi.org/10.1080/07434610310001621083

Shriver, M. D. (2007). Roles and responsibilities of researchers and practitioners for translating research to practice. Journal of Evidence-Based Practices for Schools, 8, 4-25.

Simpson, R. L. (2005). Evidenced-based practices and students with autism spectrum disorder. Focus on Autism and Other Developmental Disabilities, 20, 140-149.

Tarbox, R. S., Ghezzi, P. M., \& Wilson, G. (2006). The effects of token reinforcement on attending in a young child with autism. Behavioral Interventions, 21, 155-164. http://dx.doi.org/10.1002/bin.213

Topping, J. S., \& Crowe, J. T. (1974). Comparison of three response elimination procedures following FI and VI reinforcement training in humans. Bulletin of the Psychonomic Society, 3, 49-52.

Van Buskirk, S. E., \& Simpson, R. L. (2013). Meteorological variables and behavior of learners with autism: An examination of possible relationships. Focus on Autism and Other Developmental Disabilities, 28, 131-137. http://dx.doi.org/10.1177/1088357612475302

Walker, A. N., Barry, T. D., \& Bader, S. H., (2010). Therapist and parent ratings of changes in adaptive social skills following a summer treatment camp for children with autism spectrum disorders: A preliminary study. Child Youth Care Forum, 59, 305-322. http://dx.doi.org/10.1007/s10566-010-9110-x

Wheeler, J. J., Baggett, B. A., Fox, J., \& Blevins, L. (2006). Treatment integrity: A review of intervention studies conducted with children with autism. Focus on Autism and Other Developmental Disabilities, 21, 45-54. http://dx.doi.org/10.1177/10883576060210010601

Zane, T., Davis, C. L., \& Rosswurm, M. (2008). The cost of fad treatments in autism. Journal of Early and Intensive Behavior Intervention, 5, 44-51.

\section{Copyrights}

Copyright for this article is retained by the author(s), with first publication rights granted to the journal.

This is an open-access article distributed under the terms and conditions of the Creative Commons Attribution license (http://creativecommons.org/licenses/by/3.0/). 